\title{
Implantação do curso de graduação em saúde coletiva: a visão dos coordenadores
}

\author{
The implementation of undergraduate courses in public health: \\ the viewpoint of the coordinators
}

Soraya Almeida Belisário ${ }^{1}$

Isabela Cardoso de Matos Pinto ${ }^{2}$

Marcelo Eduardo Pfeiffer Castellanos ${ }^{2}$

Tania Celeste Matos Nunes ${ }^{3}$

Terezinha de Lisieux Quesado Fagundes ${ }^{4}$

Célia Regina Rodrigues Gil ${ }^{5}$

Raphael Augusto Teixeira de Aguiar ${ }^{6}$

Solange Veloso Viana ${ }^{2}$

Guilherme Torres Corrêa ${ }^{7}$

${ }^{1}$ Departamento de Medicina Preventiva e Social, Faculdade de Medicina, Universidade Federal de Minas Gerais. Av. Alfredo Balena 190/7, Santa Efigenia. 30130-100 Belo Horizonte MG.soraya@ nescon.medicina.ufmg.br ${ }^{2}$ Instituto de Saúde Coletiva, Universidade Federal da Bahia.

${ }^{3}$ Departamento de Escola de Governo em Saúde, Escola Nacional de Saúde Pública, Fundação Oswaldo Cruz.

${ }^{4}$ Instituto de Saúde Coletiva, Universidade Federal da Bahia.

${ }^{5}$ Departamento de Saúde Coletiva, Centro de Ciências da Saúde, Universidade Estadual de Londrina.

${ }^{6}$ Nescon, Faculdade de Medicina, Universidade Federal de Minas Gerais. ${ }^{7}$ Faculdade de Educação, Universidade de São Paulo.
Abstract Undergraduate courses in Public Health are now a reality in Brazil. The main goal of this article is to present the viewpoints of the coordinators of these courses on the process of their creation and implementation, emphasizing their contextual and procedural elements. Ten actors working in eight different institutions were interviewed and the interviews were submitted to content analysis as proposed by Bardin. The results showed that the creation of such courses resulted from a long process of discussion on the field of Public Health, and was hastened by some important decisions in Brazilian education, including the Program to Support Restructuring and Expansion Plans of Federal Universities. The testimonies of the coordinators enabled the researchers to understand the context prior to the proposal and the way it was developed by each university, making it possible to establish not only the aspects common to each institution, but also their specificities. Currently, these courses have the purpose of training professionals focused on the different areas of health services, especially those related to the Unified Health System (SUS), representing an irreversible advance in the field of Public Health.

Key words Public health, Undergraduate courses, Training, Health worker, Human resources in health, Health professionals
Resumo Os Cursos de Graduação em Saúde Coletiva são hoje uma realidade. O objetivo deste artigo é apresentar a visão dos coordenadores desses cursos sobre o processo de criação e de implementação dos mesmos, com destaque para seus elementos contextuais e processuais. Foram entrevistados dez atores integrantes de oito instituições de ensino superior, e estas entrevistas foram submetidas à análise de conteúdo proposta por Bardin. Os resultados demonstraram que a criação dos cursos advém de longo processo de discussão no campo da Saúde Coletiva e foi impulsionada por alguns marcos na educação brasileira, entre eles o Programa de Apoio a Planos de Reestruturação e Expansão das Universidades Federais. Os depoimentos dos coordenadores permitiram resgatar os antecedentes da proposta e seu percurso nas diferentes instituições de ensino, além de estabelecer os pontos comuns e os específicos de cada processo. Atualmente, esses cursos, implantados e em andamento, se propóem a formar profissionais voltados para os diferentes niveis do sistema de saúde, em especial para aqueles integrantes do Sistema Único de Saúde, constituindo-se como um processo irreversivel no campo da Saúde Coletiva.

Palavras-chave Saúde coletiva, Graduação, Formação, Sanitarista, Recursos humanos em saúde, Profissionais de saúde 


\section{Introdução}

Os Cursos de Graduação em Saúde Coletiva (CGSC) são hoje uma realidade em diversas instituições de ensino superior no Brasil, expressando um passo fundamental na expansão e consolidação das práticas de ensino estruturadas neste campo. A discussão sobre sua pertinência remonta a uma história de debates, polêmicas e amadurecimento, em que se evidenciou a necessidade da formação de um profissional com identidade específica, diferente daquela propiciada por outras graduações ${ }^{1}$, e reconheceu-se que a formação apenas na modalidade pós-graduada não responde suficientemente, em volume e agilidade, à crescente demanda por profissionais de SC no Brasil ${ }^{2}$.

A criação dos CGSC foi oportunizada por demandas dos setores da educação superior e do trabalho em saúde, as quais foram transformadas em políticas nacionais de expansão do número de vagas e cursos, bem como de postos de trabalho na área de SC.

Entre os marcos regulatórios desse processo, tem-se a Lei de Diretrizes e Bases da Educação Nacional $^{3}$, as Diretrizes Curriculares Nacionais para os cursos de Graduação ${ }^{4}$ e o Programa de Apoio a Planos de Reestruturação e Expansão das Universidades Federais (Reuni) ${ }^{5}$. Entre as diretrizes do Reuni, instituído em 2007, destacamse a proposição do aumento de vagas de ingresso, principalmente noturnas, e a determinação da diversificação das modalidades de graduação ${ }^{5}$.

Associa-se a isso o fato de que a construção do SUS gerou forte expansão da oferta de serviços, programas e ações de saúde, especialmente na Atenção Básica. Trata-se de umcontexto marcado por avanços e retrocessos ${ }^{6}$, que aponta para desafios a serem superados, tais como demandas referentes a novos perfis profissionais mais focados no contexto do trabalho em saúde no SUS ${ }^{7-}$ ${ }^{9}$. Requisitam-se, portanto, profissionais de SC com uma formação que contemple a diversidade de inserções e atribuições presentes na atual conformação do sistema de saúde, possibilitando que atuem em todos os seus níveis.

Muitos foram os movimentos realizados visando a impulsionar a discussão da Graduação em Saúde Coletiva (GSC). O Instituto de Saúde Coletiva da Universidade Federal da Bahia (ISC/ UFBA), criado nos anos 1990, representou um lócus de pensamento e discussão acerca do tema $^{10}$. Registra-se também a realização de duas oficinas, uma em 2002, em Salvador, e outra em 2003, em Brasília, promovidas pelo ISC/UFBA ${ }^{11}$, em parceria com a Associação Brasileira de Saúde Coletiva (Abrasco), a Organização Pan-Americana da Saúde (OPAS), o Ministério da Saúde (MS) e outras universidades, para a discussão da pertinência e viabilidade da criação de um CGSC. As discussões se intensificaram, ainda que sem encontrar condições objetivas propícias para se desdobrar na abertura de tais cursos ${ }^{12}$.

Em 2008, identificando no Reuni uma oportunidade, o ISC/UFBA promove um seminário sobre os CGSC, contando com a participação de diversas universidades, e, em 2009, são abertos vários cursos em universidades federais do país. Essa situação motivou a realização da pesquisa "Análise da implantação dos cursos de graduação em Saúde Coletiva em diferentes regiões do Brasil", desenvolvida pela Abrasco, por meio do seu Grupo Temático Trabalho e Educação na Saúde, com apoio e financiamento da OPAS e da Secretaria de Gestão do Trabalho e da Educação na Saúde do Ministério da Saúde (SGTES/MS).

O objetivo deste artigo é apresentar a visão dos coordenadores dos CGSC sobre o processo de criação e de implantação desses cursos no Brasil, com destaque para seus elementos contextuais e processuais.

\section{Método}

Trata-se de pesquisa qualitativa e exploratória. Neste artigo, são apresentados os resultados de entrevistas semiestruturadas realizadas em 2010 com coordenadores de oito cursos de CGSC (UFMG; UFBA; UFRJ; UFRN; UFAC; UFMT; UFPR / Litoral, e UNB/Ceilândia), em funcionamento naquele ano. Em dois deles, UFRJ e UFPR / Litoral, por razões inerentes ao seu funcionamento, foram realizadas entrevistas com dois outros atores-chave.

A pesquisa foi aprovada pelo Comitê de Ética em Pesquisa (COEP) do ISC/UFBA, ETIC, sendo aplicado a todos o "Termo de Consentimento Livre e Esclarecido”.

As entrevistas abordaram o contexto político-institucional e as características do processo de criação e implantação dos CGSC. Todas foram gravadas, transcritas e submetidas à análise de conteúdo proposta por Bardin ${ }^{13}$. Após a leitura flutuante do material, foram definidas as seguintes categorias de análise: processo de criação/contexto político-institucional; facilidades; dificuldades; relações intrainstitucionais e interinstitucionais; participação dos docentes e discentes e expectativa dos coordenadores. 
que remetem à diversidade, riqueza e não linearidade do processo de criação e implantação dos CGSC, tendo sido constatados pontos comuns e especificidades nos cursos estudados.

Foram identificadas diferenças com relação ao lócus institucional de implantação dos cursos - unidades acadêmicas responsáveis por cursos tradicionais de formação profissional em saúde, Institutos ou Núcleos de SC e novos campi universitários.

No primeiro caso, os entrevistados afirmaram que a criação dos CGSC baseou-se em fatores como: constatação da necessidade de se ter profissionais com formação e perfil específicos para a gestão; demanda persistente de capacitação para gestores na área da saúde; tradição em se trabalhar com os serviços em diferentes modalidades de formação; conhecimento e apropriação de outras experiências em andamento; necessidade de se atender à demanda colocada pelos gestores, pela comunidade e pela própria universidade.

A gente percebeu que toda vez que terminava um curso de gestão [...] hospitalar [...] de recursos humanos [...] [ou um] curso para os gestores mesmo de uma forma mais ampla [...] [ou para] conselheiros de saúde [...] sempre ficava uma demanda colocada de uma forma muito clara por uma qualificação de um gestor na área da Saúde Coletiva (E9).

No segundo caso, além das justificativas anteriores, a criação dos cursos se insere em um processo de desenvolvimento das unidades que os sediam, representando um passo decisivo de sua consolidação político-institucional no contexto universitário. Para um dos entrevistados, o desejo de constituir unidade acadêmica plena representou um fator político-institucional mobilizador da abertura da GSC, uma vez que, na estrutura organizacional da universidade, as unidades com cursos de graduação obtêm melhor representatividade política nos espaços de decisão.

[...] a ideia de que uma unidade precisa ter curso de graduação, porque se nós fôssemos uma unidade com curso de pós-graduação nós não seriamos uma unidade completa [...] a rigor todas as unidades da Universidade [...], exceto nós até dois anos atrás, têm um curso de graduação. Nós fomos exceção por dez anos e isso nos custou. Por exemplo, sempre fomos preteridos na votação de vários conselhos, porque não tínhamos graduação (E1).

Outro entrevistado relata que o curso foi proposto inicialmente em um Núcleo de Estudos em Saúde Coletiva (NESC), ainda naquele momento subordinado à estrutura da Faculdade de Medicina, sofrendo resistências só superadas após a constituição do Instituto como unidade acadêmica.

[...] foi aprovado pela maioria dos colegas do NESC. O grande problema [é que] o NESC, não sendo um instituto, nem uma unidade acadêmica [...] só poderia propor [...] [o] curso [...] Fomos ao Departamento de Medicina Preventiva, discutimos a proposta [...] foi aprovada [...] levada à congregação da Faculdade de Medicina [...] Ela ficaria agregada na Faculdade de Medicina até a criação do Instituto [...] [Então] a graduação viria para o IESC [...] A Faculdade de Medicina nunca colocou isso para discussão na congregação. O projeto ficou ali engavetado [...] Nós fomos criando o instituto [...] Passou por unanimidade a criação do instituto, portanto somos agora uma unidade acadêmica. Então, nós agora podemos propor a criação de um curso de graduação (E2).

Outro depoimento aponta o desejo de integrantes de um departamento de SC, inserido em um Centro de Ciências da Saúde, de se transformar em Instituto e, com isso, oferecer um leque de formação que contemplasse graduação e pósgraduação.

O Departamento de Saúde Coletiva era o único departamento que não tinha cursos [...] e respondia pelos conteúdos e pelas questões que são da própria Saúde Coletiva nos cursos [...] Há bastante tempo que o departamento vinha tentando se estruturar pra criação de um [...] Instituto de Saúde Coletiva. A pós-graduação é em Ciências da Saúde, apesar de Saúde Coletiva ser uma das áreas. Então, se começou a pensar a possibilidade de se ter um instituto, de se ter uma pós-graduação em Saúde Coletiva e que gerasse áreas e linhas [...] No início, pensava na graduação em si, mas se pensava mais na criação do Instituto e na oferta da pós. Logo depois... começou essa discussão [...] já vinha participando desses debates e começou a trazer essa ideia de se ter o curso [...] $O$ próprio reitor na época tinha dito: "olha essa discussão ficaria muito mais organizada se a gente tivesse possibilidade de discutir graduação e pós-graduação de uma forma articulada" (E5).

A expansão dos campi universitários proposta pelo Ministério da Educação também propiciou a criação de um dos CGSC, devido à autonomia conferida ao mesmo e, sobretudo, pelo fato de ser este um curso novo.

O Campus [...] surgiu do projeto de expansão de campi universitários do MEC. [...] Quando foi 
aprovada a criação do campus o conselho universitário ele deu liberdade para o setor abrir os seus cursos (E7).

A gente trabalha com cursos que a gente não tem, não pode recriar cursos que existam [...] não podemos trabalhar com os cursos tradicionais. Então, a oferta de cursos aqui tem que partir de cursos que não são os tradicionais dentro da universidade (E10).

Em relação ao tempo de discussão e maturação da ideia, alguns depoimentos evidenciaram ser esta uma discussão antiga.

O processo de criação do CGSC [...] nasceu com o ISC, quando nós fizemos o projeto de desenvolvimento [...] marcado pela separação do Departamento de Medicina Preventiva. O projeto incluía a graduação (E1).

[...] surgiu a ideia há dez anos... em uma conversa informal [...] falando que um dos objetivos seria a construção de um curso de Saúde Coletiva [...] (E3).

Outros depoimentos convergem na definição do Reuni como catalisador e desencadeador tanto das propostas mais antigas e que se encontravam em processo de maturação, como daquelas cuja discussão era mais inicial.

O curso foi motivado pelo Reuni [...] foi construído na proposta do Reuni. O projeto todo foi encaminhado por essa proposta. Os professores todos que estão entrando agora são pela proposta do Reuni, tem professores que estão entrando agora só para o curso (E8).

O Reuni significou carga horária docente, vaga, infraestrutura, dando viabilidade ao projeto do curso (E1).

Além do Reuni, um dos entrevistados aponta a participação da comunidade como outro elemento impulsionador no processo de abertura do curso.

Com o Reuni houve uma conversa com o hoje vice-reitor que achou que seria a época de colocarmos um outro curso aqui, e foi feito um levantamento com a comunidade e entre os cursos mais votados foi o de Saúde Coletiva. Na época, eu imaginei [...] será que a comunidade sabe o quê que é Saúde Coletiva? (E6).

Observa-se, em alguns casos, a participação de gestores de diferentes setores - público, privado e filantrópico.

[...] Fizemos uma oficina de trabalho com gestores de serviços municipais, estaduais, federais, filantrópicos e privados [...] Saímos dessa oficina [...] com a ideia do curso, o objetivo do curso e o perfil do egresso, que está no projeto (E4).

[...] Esses gestores participaram desse momento de escrever, construir o projeto político pedagó- gico para ser enviado para o Ministério da Saúde para ser aprovado pelo Ministério da Educação. E esse projeto foi construído com várias mãos, é um trabalho coletivo [...] (E9).

Tal resultado corrobora a opinião de Elias ${ }^{14}$, para quem a implementação de um programa de Graduação em Saúde Coletiva não deve ser apenas iniciativa do Aparelho Formador, como se apresenta até o momento. Antes, para se tornar uma iniciativa socialmente virtuosa, exige diálogo com os gestores de saúde, principalmente do âmbito municipal, no sentido de identificar possibilidades de alterar lógicas e práticas de saúde vigentes para o delineamento de um perfil profissional condizente com a efetivação da assistência em saúde contemporânea aos desafios políticos e sociais desse tempo ${ }^{14}$.

Para exemplificar alguns argumentos contrários ao processo, um entrevistado menciona uma mesa redonda realizada em um congresso da Abrasco sobre essa temática, a qual foi pautada por intensas e emocionadas discussões:

A argumentação principal das pessoas contrárias foi: [...] olha, acabamos de criar diretrizes curriculares, acabamos de definir diretrizes fundamentais pra medicina, pra todas as profissões de saúde, inserindo conteúdos fortes de Saúde Pública, Saúde Coletiva nessas disciplinas [...] Se criasse esse curso agora vai fracionar esse movimento, vai enfraquecer esse movimento [...] (E2).

Como contra-argumento, afirmava-se que a abertura dos CGSC representaria um reforço da área, respondendo à necessidade de formação antecipada e em larga escala, impostas pelo desenvolvimento do SUS e pelo avanço da Reforma Sanitária.

A minha defesa foi exatamente o inverso [...] Vai reforçar [...] dando força à argumentação de necessidade de formação de pessoas [...] Custava caro pro Brasil formar pós-graduando [...] de Saúde Coletiva, sanitaristas. Um país com graves problemas sanitários, formar sanitaristas só na pósgraduação [...] era um custo enorme pro governo. Obviamente não houve uma conclusão dessa mesa redonda da Abrasco, mas foi fantástica, realmente foi um momento histórico [...] (E2).

O entendimento de que o movimento da Reforma Sanitária precisava de mentes e braços, através de massa crítica e a formação pós-graduada não seria suficiente para prover [...] quadros pro desenvolvimento do sistema de saúde, para o SUS (E1).

Tais achados corroboram as colocações de Paim, que classifica a formação pós-graduada como tardia, apontando o fato de esta ter um resultado limitado quanto à formação de sani- 
taristas com uma relação custo-benefício desfavorável $^{2}$.

O papel da Abrasco ao longo de todo o processo foi citado por um entrevistado. Constatou-se um movimento interessante vivido pela Associação, que vai de uma resistência inicial a uma abertura progressiva e culmina no acolhimento da proposta.

A Abrasco tinha algumas resistências, mas resolveu bancar a discussão. Como tinham duas afiliadas, uma delas de grande relevância na saúde pública, que era o ISC [...] a Abrasco resolveu acolher e convocou um seminário nacional [...] lá no ISC [...] A presença do reitor da Universidade, mostrando [...] [que] era um projeto verdadeiramente institucional, foi fantástica. Ficou um debate muito rico de pessoas contra e pessoas totalmente a favor (E2).

Um marco dessa mudança foi a inclusão dessa temática no IX Congresso Brasileiro de Saúde Coletiva, promovido pela entidade em 2009, em Recife. Na programação, uma mesa e uma oficina que objetivaram discutir a inserção desse novo ator no campo da SC, mapear os processos mais significativos que envolviam a implantação desses cursos e sugerir agendas pertinentes aos seus desdobramentos. Esta oficina defendeu a criação do Fórum de Graduação em Saúde Coletiva (FGSC), posteriormente constituído e abrigado na Abrasco.

Naquele momento, a Abrasco ainda mantinha uma posição indefinida com relação à proposta de criação dos cursos, porém um passo significativo havia sido dado. Essa situação se reflete na Carta de Olinda, elaborada naquele congresso, quando cita a GSC e aponta para mudanças, afirmando que "novos atores se incorporaram ao campo da formação em saúde coletiva, e a Graduação na área mostrou sua face nacional, definindo desdobramentos fundamentais no interior da própria Abrasco"15.

A inclusão dessa pauta na agenda da Associação tornou-se obrigatória e irreversível, resultando em importantes desdobramentos: criação do FGSC, incorporação dos cursos e dos alunos de GSC, além da mudança de seu nome.

Por fim, o estabelecimento de parcerias também foi pontuado como facilitador do processo de criação dos CGSC. No âmbito interno da universidade, apontou-se a participação de diferentes unidades, núcleos de pesquisa e a formação de comissões para a discussão da proposta. No âmbito externo, a participação de outras instituições, numa relação de assessoria teórica e pedagógica, bem como a utilização de projetos e experiências em estágios mais amadurecidos de discussão, foram inspiradores do processo.

A gente fez a parceria com a Medicina [...] Nós fomos para a Medicina Preventiva, exatamente para ter esse viés do trabalho, da saúde ambiental, de qualidade de vida [...] Os três departamentos da Escola de Enfermagem, a Administração, Economia, Demografia e Medicina Preventiva (E4).

As discussões que estava havendo na Bahia, inclusive aquele documento [...] do Jairnilson sobre a crise da saúde pública... Isso teve uma certa repercussão dentro do Instituto de Saúde Coletiva [...] Foi criada uma comissão de avaliação, de implantação para o curso [...] professoras [...] da área de ciências sociais [...] elas procuraram entender como é que estava esta discussão no resto do país e participaram [...] daquele encontro lá no Rio Grande do Sul, que teve sobre os cursos de graduação em Saúde Coletiva. E praticamente ali foi a reformulação do desenho do curso (E8).

\section{Participação Docente}

A despeito das especificidades de cada processo, a participação dos docentes na formulação e implementação dos cursos foi vista de forma positiva pela maioria dos entrevistados, mesmo nos locais em que houve ou ainda há docentes resistentes à proposta.

Até hoje tem pessoas que são refratárias ao curso, algumas inclusive se colocam dessa forma, mas que fantasticamente e democraticamente estão ministrando aula no curso e inclusive estão gostando (E2).

Em alguns cursos, a construção da proposta se deu de forma conjunta, e todos puderam expressar sua opinião, colocar divergências, chegando-se a uma decisão coletiva.

Eu nunca perguntei a um ou outro docente se ele é a favor do curso de graduação em Saúde Coletiva [...] a gente não faz esse tipo de pergunta, aquilo que o plenário aprova é a vontade do coletivo e vira realidade se puder. Durante as discussões teve divergências sem dúvida (E1).

Em outro curso, os docentes tiveram grande participação na construção da proposta.

A gente [...] conseguiu colocar praticamente todos os professores que têm interesse nessa ideia em torno da construção do projeto político pedagógico. Todo mundo contribuiu (E9).

Com intensidades diferentes, os docentes são vistos como potenciais colaboradores. Contudo, por vezes é esperado que aqueles concursados especificamente para os CGSC se constituam como o núcleo duro de sua condução. 
No fim todo o corpo docente e aí não são só os docentes do quadro do instituto, são potenciais colaboradores. Nós sabíamos que seus compromissos assumidos com pós-graduação, pesquisa [...] Só novos professores poderiam de fato constituir um grupo duro no desenvolvimento e implantação do curso (E1).

A entrada desses novos atores, de formações diferenciadas, detentores de potencial técnico e reflexivo, é vista positivamente.

A Escola deu uma expandida [...] na maneira de pensar [...] entraram professores tão bons, que a gente tem alguns que já estão inseridos na pósgraduação, com credenciamento pleno, com publicação [...] Nós temos cientista social [...] enfermeiro [...], psicólogo, [...] estatístico, epidemiólogo (E4).

Outra questão apontada foi a participação de docentes de outros departamentos e unidades acadêmicas.

A articulação com outros cursos da saúde, a gente tem a participação [...] de professores do Instituto de Bioquímica, de Ciências Biomédicas, da Biologia (E2).

\section{Participação Discente}

A participação discente tem se dado de forma diversificada e ativa, contemplando representação em diferentes órgãos colegiados da universidade, busca por atividades extracurriculares, inserção em projetos de pesquisa e participação em eventos.

A gente procurou acolher e [...] contar para eles como que o projeto foi construído e o quê que a gente esperava deles. E eles se empoderaram de tal forma com essa ideia de ser gestor, que começaram a procurar atividades extracurriculares, entrar como bolsistas PET, participar de evento, fazer avaliação do curso, sugerir bibliografia. Os alunos estão participando ativamente da construção do curso (E4).

Assim, num movimento por conquista de espaço e legitimação institucional e social, observou-se a criação de Centros Acadêmicos, participação em eventos e produção de material informativo e de divulgação distribuídos em eventos diversos.

Também foram relatados movimentos de aproximação e interação com alunos de outros cursos da área da saúde, facilitados, entre outras questões, pela existência de disciplinas comuns.

A gente está achando que uma estratégia, um ponto comum seria esta interação dos próprios alunos com os alunos dos outros cursos de graduação (E8).

Eles estão interagindo com alunos de outros cursos de saúde. Tem disciplinas, hoje, optativas, que são dadas [...] para os três cursos (E4).

Os discentes foram definidos por alguns entrevistados como mobilizados, detentores de organização política avançada e bastante envolvidos na construção e desenvolvimento do curso, capazes de perceber conteúdos necessários ao gestor e, com isso, criar novas necessidades. A despeito disso, os mesmos têm dúvidas acerca da profissão e das atribuições do profissional nela formado.

[...] eles passam por uma crise de identidade... eles têm dúvidas se realmente são gestores ou sanitaristas (E5).

A regulamentação da profissão e as possibilidades de inserção no mercado de trabalho são apontadas como questões centrais para os estudantes dos CGSC, uma vez que muitos já se encontram no mercado por possuírem outra graduação.

\section{Facilidades e Dificuldades}

Foram elencadas facilidades de natureza interna e externa às instituições. Entre as internas, estão as mudanças institucionais e regimentais empreendidas no intuito de permitir a criação de um curso com um novo formato, os apoios recebidos de diferentes instâncias da universidade e o engajamento dos docentes.

As facilidades [...] estão baseadas fundamentalmente no fato de que esse continua sendo um projeto de todo o Instituto de Saúde Coletiva [...] O colegiado se ampliou por decisão do plenário pra incluir todo o trabalho de graduação, aumentando a responsabilidade desse colegiado [...] Acho que indica uma sustentação institucional [...] quando o projeto ganha vida própria, ele segue o seu curso. Eu acho que essa é a grande facilidade que nós temos (E1).

Outras facilidades foram a melhoria da infraestrutura, a conquista de espaço físico e a realização de concursos para a contratação de professores.

Temos recursos razoáveis para construir prédio novo, vamos ter instalações modernas funcionais, vamos ter um andar só para a gente [...] laboratório de informática [...] Enfim, uma série de providências que estão sendo tomadas e que vão criar um contexto bem favorável para dar continuidade ao curso (E9).

Dentre as facilidades externas, citam-se articulações com instituições que vivenciavam processo semelhante, facilitando a discussão e a implantação da iniciativa em diferentes instituições.

Diferentes tipos de resistência - genérica ao novo, dos docentes, ao novo profissional a ser 
formado -, impedimentos burocráticos, fragilidades de infraestrutura, falta de pessoal e divergências quanto a concepções pedagógicas e metodológicas sobre o curso em SC foram apontados como dificuldades enfrentadas.

Dentro do próprio grupo teve alguma resistência [...] Tinham duas professoras [...] que queriam que fosse formado um gestor para o SUS. Ai, nós discutimos muito [...] e falamos [...] "vai ser formado [...] prioritariamente para o SUS, mas não só para o SUS" (E4).

O modelo pedagógico a ser adotado também foi um objeto de resistência identificado por alguns entrevistados. Destaca-se a dificuldade de criação de um curso novo, que estivesse fora da estrutura tradicional de disciplinas, o que demandou a adaptação do projeto às exigências formais. Tal fato levou à convivência de dois modelos pedagógicos: a estrutura curricular modular proposta para o CGSC passou a conviver com o modelo estruturado em disciplina, desenhado para os demais cursos.

A gente pensava em uma coisa integrada... e quando chegava na Pró-Reitoria de graduação tinha que traduzir tudo em caixinhas, em fluxo, em carga horária. [...] resolvemos: "tudo bem, há um protocolo na instituição então vamos fazer uma estrutura careta, tradicional, cheia de caixa e corrompemos essa estrutura na prática." E os professores conseguiram fazê-lo (E1).

As muitas demandas surgidas no processo e a dificuldade de operacionalizá-las, como a realização de vários concursos, a construção de unidades, entraves administrativos na utilização e gasto dos recursos, também foram barreiras lembradas.

$O$ "day after", o vestibular, o divulgar, o concurso e o aparelho burocrático da universidade, não azeitado para dar conta da imensa demanda gerada pelo governo federal; nunca tivemos tantos concursos [...] em tão pouco tempo (E2).

A desaceleração da implantação do Reuni nos últimos tempos, o que levou a uma diminuição dos concursos para preenchimento das vagas e à sobrecarga dos docentes, foi outra dificuldade relatada.

Eu colocaria como dificuldade a questão dos recursos humanos [...] porque hoje precisamos juntar a política de se ter um curso novo com uma expansão, mas precisamos de recursos humanos pra trabalhar nesse curso (E10).

Desacelerou muito a implantação do Reuni e isso se revelou também na desaceleração das vagas docentes [...]. Isso pode também comprometer o projeto no futuro, porque nós não podemos susten- tar curso com substituto, curso novo precisa ser sustentado com quadro efetivo [...] (E1).

A diversidade dos alunos, muitos dos quais apresentavam deficiências de aprendizado, de leitura e compreensão de textos, aliada à escassez de material adequado para a graduação na área, também surgiram como obstáculos.

Existe certa diversidade [...] você tem aquele que vem de um nivel com mais dificuldade, $e$ [aquele] que tem um pouco mais de condição de compreender um texto mais difícil [...] Nós temos no Brasil muito pouca coisa produzida para a graduação na Saúde Coletiva, temos para pós (E9).

\section{Relações intra e interinstitucionais}

Duas propostas anteriores ao Reuni enfrentaram, nos primeiros momentos, dificuldades internas ao contexto universitário para a criação do curso.

A primeira, já mencionada, representada pela tentativa de criação do CGSC no âmbito da Faculdade de Medicina, só se viabilizou após a criação do instituto, auferido à unidade acadêmica.

A outra, a despeito do amadurecido estágio de discussão, não conseguiu as condições necessárias à criação do curso, o que foi propiciado pelo Reuni.

Já tínhamos acompanhado um pouco a experiência de outro Estado [...] de não conseguir fazer por desentendimento com a medicina [...] Nós e eles éramos os dois únicos projetos razoavelmente formatados no país [...] é curioso que aí, quando surgiu o Reuni, era o único cimento [...] esse jeito [...] de fazer as coisas às vezes muito pragmático, a ponto de deixar um projeto sentado dez anos porque achava que não tinha condições objetivas pra realizá-lo (E1).

Contudo, vencidas as resistências iniciais e com o Reuni, os cursos contaram com amplo apoio institucional.

Houve apoio da direção sim, da reitoria sim porque tudo que era apoio Reuni a administração central apoiava, e o curso foi finalmente aprovado no Conselho de Ensino da Universidade (E1).

Apoio total da Reitoria [...] apoio da PROGRAD, muito grande (E4).

Não houve dificuldades, a gente não teve que fazer nenhum tipo de justificativa extra com relação ao tema Saúde Coletiva, por ser esse curso (E7).

Para um dos entrevistados, a criação do curso possibilitou maior interação entre as subáreas da própria SC:

O curso [...] trouxe um mecanismo de interação entre as áreas de conhecimento da saúde cole- 
tiva - a epidemiologia e as ciências sociais e a política de planejamento e gestão (E8).

Verificou-se uma boa relação dos cursos com os gestores dos serviços de saúde, exemplificada de diferentes formas.

Eles ficaram entusiasmadíssimos, receberam a notícia desse nosso projeto de criação do curso de graduação com muita satisfação e com uma perspectiva mesmo de acolher essa ideia de uma forma muito positiva (E9).

O Secretário Municipal de Saúde fez a aula inaugural da primeira turma do curso (E4).

A gente por diversos momentos conversou com a gestora da área da saúde, participou com a ex-secretária de saúde do município [...] encontros periódicos na regional de saúde para discutir o projeto pedagógico do curso junto com outros gestores (E10).

O conselho com os secretários municipais de saúde que participou das primeiras discussões, na reformulação eles vieram para ajudar a discutir, principalmente com a Escola de Saúde Pública (E8).

No que tange à articulação dos cursos e serviços para a realização de estágios na rede, as relações também se apresentaram de forma positiva e promissora, com negociações em andamento.

A partir do próximo semestre e do quarto período, pelo projeto, já é hora deles começarem a se inserir nos cenários de prática. Então, nós já estamos fazendo contatos [...]. Essa fase de negociação dos estágios é, inclusive, uma fase de retorno para as instituições que discutiram (E4).

\section{Expectativas}

Nesta categoria, os depoimentos apontaram para questões como mercado de trabalho, reconhecimento profissional, inserção dos egressos nos serviços, regulamentação da profissão e reconfiguração do campo da SC.

Pontuou-se que o sanitarista é uma profissão necessária, dinâmica, em evolução e que o sanitarista do futuro deverá integrar os novos conhecimentos que estão por construir.

A necessidade de sanitarista pra mim é inquestionável, mercado de trabalho terá e muito (E2).

$E u$ acho que existem possibilidades reais da inserção desse profissional [...] a demanda do próprio serviço de saúde [...] é uma luta [...] que envolve muitos fatores (E10).

O sanitarista de hoje não é o que será daqui dez anos [...] é a evolução do conhecimento [...] da dinâmica do mundo como um todo é que vai definir a entrada dele no mercado (E3).

Outra expectativa foi a de que os gestores promovam concursos públicos que contemplem este novo profissional e, consequentemente, realizem mudanças em seus planos de cargos e carreiras para incluí-los.

É necessário que esses gestores sinalizem... e que tenham interesse em fazer as mudanças legais [...] que resultem [...] na possibilidade desses egressos encontrarem [...] chances de trabalhar pro SUS [...] (E1).

Nesse sentido, o concurso é visto como estratégia de inserção e legitimação profissional do sanitarista, o que provavelmente implicará disputas com os demais profissionais sanitaristas.

Sobre a inserção dos egressos nos serviços, a expectativa é de que a mesma aconteça do nível local ao central, nas mais variadas posições e papéis na organização político-administrativa dos serviços de saúde.

Espero que nosso egresso tenha condição de trabalhar lá no interior do Amazonas se ele quiser ou lá no Gabinete do Ministro da Saúde (E3).

$\mathrm{Eu}$ acredito que o nosso profissional, porque ele tá vendo não só gerenciamento em saúde [...] Existem muitos projetos que às vezes não vão adiante porque não tem aquele profissional que saiba administrar serviços de saúde [...] o nosso vai saber fazer isso. Ele sabe andar no campo da administração e no campo da saúde (E6).

Foi também pontuada a necessidade de os alunos se organizarem para discutir a regulamentação da profissão junto às autoridades competentes. Neste sentido, acredita-se que o FGSC e o Conselho Nacional de Saúde terão papel de destaque no encaminhamento dessa discussão.

Precisamos totalizar esse movimento e tem muito a fazer, todos eles, desde o Congresso Nacional até o município [...] sob pena de [...] ter muito apoio [...] todo mundo concordar [...] e ficarem essas pessoas aí feito zumbi, profissionais com crise de identidade [...] porque ou não são reconhecidos, ou não são aceitos, ou a sociedade sequer os conhece [...]. Eles precisam se fazer conhecer na sociedade brasileira (E1).

Por fim, outra expectativa levantada foi a de que o CGSC irá contribuir para a reconfiguração do campo, impondo mudanças na atual formação em SC e exigindo maior aprofundamento por parte dos cursos de pós-graduação.

O curso de graduação vai contribuir [...] enormemente pra reconfiguração da nossa área [...]. A "pós" [...] vai ter que ser repensada e, a meu juízo, para o avanço do campo, para o avanço da ciência e tecnologia e inovação na área da saúde, para o avanço das questões de saúde, da sociedade brasileira (E2).

Vai mudar a estrutura da formação, um mestrado ou doutorado em Saúde Pública vai ter que 
Os Cursos de Graduação em Saúde Coletiva compõem um conjunto de cursos implantados e em andamento nas cinco regiões do país. A despeito de terem vivenciado processos diferenciados em seu percurso, constataram-se convergências em relação a contextos mais amplos em que as propostas foram formuladas e implantadas.

A formação em Saúde Pública se iniciou no Brasil nos anos 1920, pela pós-graduação ${ }^{16}$, e passou por diversas transformações no seu escopo e amplitude. Historicamente e em consonância com os diferentes momentos políticos e de organização dos serviços de saúde, o sanitarista conformou diferentes faces: campanhista, desenvolvimentista, racionalizadora/modernizante, médico-social, generalista e gerencial ${ }^{17}$. Entretanto, a necessidade de se avançar na construção e consolidação do SUS passou a demandar um novo profissional que vá além dessas faces já estabelecidas.

Assim, Paim afirma que o SUS precisa de profissionais aptos a atuar em todos os níveis do sistema, incluídas aí as equipes de saúde da família, e não só nas unidades de administração central - face gerencial do sanitarista ${ }^{2}$. Neste contexto, a ideia de se completar o ciclo com a formação graduada foi progressivamente tomando corpo.

Dá-se, aqui, destaque para a Abrasco, que, até então voltada aos cursos de Pós-graduação, reconhece a magnitude desse processo e promove importantes mudanças em seu estatuto, no sentido de abrigar tanto essas novas iniciativas como seus personagens.

Este estudo traz um conjunto de evidências que apontam para o longo caminho a ser percorrido em prol da consolidação desses cursos e reconhecimento desse novo profissional. Muitos desafios estão colocados, muitas questões se encontram na agenda dos coordenadores, estudantes e gestores. O momento é rico para se obser-

varem as experiências em curso, pensar sobre elas e produzir novos estudos sobre o tema.

Por se acreditar ser este um processo irreversível, espera-se que esta pesquisa contribua não só para aprofundar o conhecimento das iniciativas em desenvolvimento, mas também para qualificar o debate em torno delas, considerando sua complexidade.

\section{Colaboradores}

SA Belisário, ICM Pinto e MEP Castellanos participaram do desenho do estudo, coleta e análise dos dados, redação do artigo e aprovação da versão para publicação; TCM Nunes e TLQ Fagundes participaram do desenho do estudo, coleta e análise dos dados, revisão crítica do artigo e aprovação da versão para publicação; CRR Gil participou da coordenação da equipe pesquisa, delineamento do estudo, coleta dos dados e aprovação da versão para publicação; SV Viana participou do desenho do estudo, coleta de dados e aprovação da versão para publicação; GT Corrêa participou do estudo, coleta de dados e aprovação da versão para publicação; RAT Aguiar participou do delineamento do estudo, revisão crítica do artigo e aprovação da versão para publicação.

\section{Agradecimentos}

Agradecemos a todos os atores que participaram desta pesquisa. 


\section{Referências}

1. Bosi ML, Paim J. Graduação em Saúde Coletiva subsídios para um debate necessário [Editorial]. Cad Saúde Pública 2009; 25(2):236-137.

2. Paim J. O objeto e a prática da Saúde Coletiva: o campo demanda um novo profissional? In: Paim J, organizador. Desafios para a Saúde Coletiva no século XXI. Salvador: EDUFBA; 2006. p. 99-116.

3. Brasil. Presidência da República. Casa Civil. Subchefia para Assuntos Jurídicos. Lei no 9.394 de 20 de Dezembro de 1996. Estabelece as diretrizes bases da educação nacional. Diário Oficial da União 1996; $231 \mathrm{dez}$.

4. Brasil. Ministério da Saúde(MS). Diretrizes Curriculares - Cursos de Graduação Brasília: MS; 2002. [acessado 2010 ago 28]. Disponível em: http:// portal.mec.gov.br/index.php?option $=$ com_content \&view $=$ article\&id $=12991 \&$ Itemid $=866$.

5. Brasil. Presidência da República. Casa Civil. Subchefia para Assuntos Jurídicos. Decreto no 6.096 de 24 de abril de 2007. Institui o Programa de Apoio a Planos de Reestruturação e Expansão das Universidades Federais - Reuni. Diário Oficial da União 2007; 25 abr.

6. Negri B, Viana ALD, organizadores. O Sistema Único de Saúde em dez anos de desafios. São Paulo: Sobravime, Cealag; 2002.

7. Brasil. Ministério da Saúde (MS). Secretaria de Políticas de Saúde. Coordenação Geral da Política de Recursos Humanos. Política de Recursos Huma nos para o SUS: balanço e perspectivas. Brasília: MS; 2003.

8. Brasil. Ministério da Saúde (MS). Coordenação Geral de Desenvolvimento de Recursos Humanos para o SUS. Regulação e Gestão de Recursos Humanos em Saúde na Perspectiva da Reforma do Estado. Brasília: MS; 1998.

9. Teixeira CF. Formação de recursos humanos para o SUS: desafios na perspectiva da mudança do modelo de gestão e atenção à saúde. Saúde Deb 1993; (41):20-23
10. Teixeira CF. Graduação em Saúde Coletiva: anteci pando a formação do sanitarista. Interface Comun Saúde Educ 2003; 7(13):163-166.

11. Universidade Federal da Bahia(UFBA). Instituto de Saúde Coletiva (ISC). Documentos básicos. Salvador: ISC, UFBA; 1994

12. Universidade Federal da Bahia. Instituto de Saúde Coletiva. UFBA, ISC. Graduação em Saúde Coletiva: pertinência e possibilidades. In: Seminário e Oficina de Trabalho, 1., 2002, Salvador. Relatório final. Salvador: UFBA; 2002.

13. Bardin L. Análise de conteúdo. 4a Edição. Lisboa: Edições 70; 2008.

14. Elias PEM. Graduação em Saúde Coletiva: notas para reflexões. Interface Comun Saúde Educ 2003; 7(13):167-170.

15. Associação Brasileira de Saúde Coletiva (Abrasco). Carta de Olinda. In: IX Congresso Brasileiro de Saúde Coletiva; Recife, nov. 2009; [acessado 2012 ago 28]. Disponível em: http://www.abrasco.org.br/UserFiles /File/AbrascoDIVULGA/2009/ABRASCAO2009 CARTADEOLINDA.pdf.

16. Labra ME. O Movimento Sanitarista nos anos 20: da conexão sanitária internacional à especialização em saúde pública no Brasil [dissertação]. Rio de Janeiro: Escola Brasileira de Administração Pública, Fundação Getulio Vargas; 1985.

17. Belisário SA. Médico Sanitarista: as muitas faces de uma ocupação [dissertação]. Rio de Janeiro: Escola Nacional de Saúde Pública; 1994.

Artigo apresentado em 03/07/2012

Aprovado em 26/09/2012

Versão final apresentada em 19/10/2012 